\title{
Kaizen as Policy Instrument: The Case of Ethiopia
}

\section{Getahun Tadesse Mekonen}

This chapter reports on the experience of Ethiopia in transferring and disseminating the Japanese concept of Kaizen, philosophy of continuous improvement. Kaizen was introduced to Ethiopia by Japan International Cooperation Agency (JICA) in 2009 and has since become a mainstay instrument of reform. It has been widely accepted and implemented by many companies. There are concerns over the transferability of Kaizen to developing countries, particularly to African countries. Issues raised by those who claim Kaizen to be unique to Japan are mostly related to its Japanese religious and cultural background. The differences between the homogenous social fabric of Japan and the diversified ethnicities of Africa are one factor raised as an impediment to Kaizen transferability. However, while these characteristics may have certain impacts, they have not hampered the transfer and dissemination of Kaizen to Ethiopia, where there are multiple ethnicities, religions, and cultures.

Three consecutive Kaizen projects, supported by JICA, have been implemented in Ethiopia since October 2009. The first pilot project was

\footnotetext{
G. T. Mekonen ( $\bowtie)$

Principal Kaizen Consultant, Addis Ababa, Ethiopia

(C) The Author(s) 2018

K. Otsuka et al. (eds.), Applying the Kaizen in Africa, https://doi.org/10.1007/978-3-319-91400-8_5
} 
undertaken to confirm the transferability of Kaizen and study how use of the concept could be expanded after the JICA project was completed. The initial introduction of Kaizen into selected pilot companies proved the receptiveness of Ethiopian companies to new initiatives and showed encouraging results in improving quality and productivity. Encouraged by the results of the project, the Ethiopian government established the Ethiopia Kaizen Institute to disseminate and expand on the results attained during the pilot project.

The second project was aimed at training Ethiopian Kaizen consultants in order to build the capacity of the institute. In this project, 57 Kaizen consultants and 133 trainers from Technical and Vocational Education and Training (TVET) Institutes received training. The Ethiopia Kaizen Institute enthusiastically launched the Kaizen movement in large-scale sugar, textile, and leather companies using trained consultants. Highly promising quantitative and qualitative changes were recorded. The change in attitudes and the creation of smooth relationships in situations where there was strong conflict between management and the workforce were the most outstanding results. The monetary values of achievements attained each year amounted to hundreds of millions of birr.

The third project, currently underway, is designed to transfer advancedlevel Kaizen knowledge, with 90 Kaizen consultants passing through this project. Around 30 companies that previously disseminated Kaizen during the pilot and second projects will be introduced to advanced Kaizen. Ethiopia designed its own local capacity-development program in collaboration with local universities, and 18 Kaizen consultants from the institute have now graduated with MSc degrees in Kaizen, 16 are in second year, and 22 are in their first year.

Ethiopia Kaizen Institute has conceived its own Kaizen transfer and development roadmap, prepared models, and crafted strategies. The roadmap plots the transfer of Kaizen from Japan over 15 years-from 2011 to 2025 - in three phases that correspond to the growth and transformation plan of the country. It has completed the first phase and the second phase will be completed in 2020.

Overall, the Ethiopian experience has proved that differences in religion, culture, and diversity are not impediments to the transfer of the 
Kaizen concept to Africa and that Kaizen could bring about dramatic changes in companies and public institutions.

This chapter consists of five sections. Section 5.1 explains how Kaizen transfer to Ethiopia was initiated, followed by Section 5.2, which illustrates the formation of the Ethiopia Kaizen Institutes. Section 5.3 discusses the Ethiopia Kaizen roadmap and strategies. The major achievements, success factors, and ongoing challenges are presented in Section 5.4. Finally, lessons that can be drawn from the Ethiopian experience are outlined in Section 5.5.

\subsection{The Landmark}

During the summer of 2008, the late Prime Minister of Ethiopia, H.E. Meles Zenawi, was discussing development issues with scholars from the Western and Eastern worlds (GRIPS 2016). Contact with Japanese academics provided him with an opportunity to learn about Kaizen. In search of better understanding, he requested that JICA provide further explanation regarding Kaizen projects and the experience of African countries. JICA honored his request by providing information and progress concerning JICA-assisted Kaizen Projects in Africa. After hearing about the productivity and quality improvement impacts of Kaizen as well as its contribution to the industrial development of Japan —initially based on small and medium-sized enterprises (SMEs) he extended his request to JICA for further assistance. In addition to these contacts, Kaizen was frequently discussed in High level Policy Dialogue forums assisted by JICA and the professional contributions of Professors Kenichi Ohno and Izumi Ohno, from the GRIPS Development Forum.

A project entitled "The Study on Quality and Productivity Improvement (Kaizen) in the Federal Republic of Ethiopia" was designed by JICA in consultation with an Ethiopian counterpart and signed by the Ministry of Industry and JICA on June 4, 2009. The project time frame was from October 2009 to May 2011 and it incorporated the following three major objectives (JICA 2011a): 
1. Formulate a national plan to enhance activity on quality and productivity improvement (Kaizen) for Ethiopian enterprises in the industrial sector;

2. Formulate a manual which can be used for quality and productivity improvement activity (Kaizen); and

3. Transfer relevant skills and techniques to the staff members of the Kaizen Unit of the Ministry of Industry.

The Ministry of Industry established a Kaizen Unit (KU) consisting of ten members and assigned a team leader. The members were drawn from the Ministry and Institutions affiliated to it, and the new team was given a written mandate to work with JICA consultants to realize the project objectives. The project was hosted by the Metal Products Development Center, which provided offices, as well as conference and training rooms for JICA consultants and the unit. JICA deployed a team of experts and their first task was to explain the concept of Kaizen by opening discussions between the unit members and JICA experts.

When the project started, the Ministry and all institutions affiliated to it, including the Metal Products Development Center, were preoccupied with business process reengineering (BPR) projects. BPR is a change tool developed in the USA that helps to define processes, identify valueadding and non-value-adding activities, and reduce or eliminate those non-value-adding activities from processes of production and services to improve efficiency. In Ethiopia, BPR was introduced by the government to improve the efficiency of public services.

The pre-eminent place of BPR, with its goals of fundamental, drastic, and dramatic change, meant that it took us some time to be convinced of the merits of Kaizen. We were told the meaning of Kaizen as 'a small incremental change' or 'continuous improvement' by JICA experts. On top of that, none of us in $\mathrm{KU}$ had experience of working with Japanese people. The discussion took us a few weeks and, over time, the commitment of the JICA experts to enlightening us about Kaizen — along with their discipline, well-preparedness, art of mining information, and punctuality-convinced us. The more we came to know the secret of Kaizen, the more we were convinced and buried ourselves in Kaizen activities and literature. 
The first objective of the project was to transfer Kaizen knowledge and skills from JICA experts to KU members. In line with this, course modules were prepared by JICA experts and delivered with the help of classroom demonstrations, videos, and games. The major course contents were the definition of Kaizen, elimination of waste, visual management, quality control circles, problem-solving steps, seven quality control tools, operation standards, and time study. A month-long classroom training (CRT) was followed by five months of in-company training (ICT).

To select the 30 companies for the pilot project, a long list of medium and large manufacturing companies was prepared. Among the major selection criterion were that the participating companies needed to be situated within a radius of $100 \mathrm{~km}$ of the capital city. They needed to make contributions to export/import substitution, possess scale of capital, have a diverse range of products, and avoid duplication of support with other donors. The interest and commitment of management and workers was another important criterion. A national conference was held to introduce the project, to assess the interest of companies, and to facilitate registration of those who expressed a willingness to participate. The initial long list was shortened from 180 to 60 companies. Through visiting the companies, the JICA expert team and KU members identified 30 pilot companies from 5 sub-sectors, namely, (1) 10 companies in basic metal and engineering, (2) 6 in agro-processing, (3) 6 in chemical manufacturing, (4) 4 in leather, and (5) 4 in textiles. These companies were divided into three groups and each group of ten companies undertook training for a duration of six months.

The ICT had two components. The first one was to invite the owners and top management members of companies to the Metal Development Center for a one-day seminar with the objective of creating awareness on Kaizen and introducing the ICT plan. This was followed by training of Kaizen core members consisting of top and middle managerial staff, selected work stations for trial, and frontline workers in each company. The trainings were conducted by both JICA experts and KU members, based on the following steps (JICA 2011b): 
Step 1. Overview of Kaizen

Step 2. Understanding standardization of workplace environment and operations

(a) Theme-1 $5 \mathrm{~S}$

(b) Theme-2 Operation Standard and Time Study

(c) Theme-3 Elimination of Waste $(M U D A)$

Step 3. Implementing Kaizen Activities at the Company

(d) Action-1 Organizing Sort Activity

(e) Action-2 Understanding ' $3 S$ ' activities in Eliminating $M U D A$

(f) Action-3 Standardizing Operations at the Selected Workplace

Step 4. Understanding and Overview of QC Circles

(g) Theme-1 How to Organize a QC Circle/What is the QC Story?

(h) Theme-2 QC 7 Tools and QC Circle Presentations

Step 5. Organizing QC Circles at the Company

(i) Action-1 Conducting QC Circles Meetings

(j) Action-2 Conducting QC Circles Presentation Meetings

Step 6. Preparatory Work for Companywide Kaizen Activities

Checklists and formats were prepared to be used by the KU members and companies throughout their Kaizen activities. Side by side with CRT and ICT, a training program was arranged and conducted in Japan for 30 company owners and managers as well as $10 \mathrm{KU}$ members. This training program offered an important chance to observe and learn in the actual environment of Japanese companies, workers, and people. Many participants shared their judgment that Kaizen is not only a management philosophy but is also a part of Japanese 'culture'.

There were regular mini-conferences between the JICA experts and $\mathrm{KU}$ members to discuss issues requiring clarification and the challenges that periodically arose within companies. KU members took different topics, prepared presentations, and delivered them at mini-conferences as part of their self-education process. The objective of skill transfer comprised the major part of the project and it was concluded by developing 
a consultant skill matrix for KU members and future Kaizen consultants. The skill matrix was prepared based on local participant experiences of the pilot project, while also incorporating Japanese experiences. The matrix comprises Grade I (Junior Consultant), Grade II (Assistant Consultant), Grade III (Consultant), Grade IV (Senior Consultant), and Grade V (Lead Consultant). The competence requirements were improved during the second and third JICA projects, and incorporated into the Ethiopia Kaizen Institute (EKI) Strategic Roadmap and Model, which will be discussed later in this chapter. KU members were evaluated by JICA experts and ranked into Grade II (Assistance Consultant) and III (Consultant). The matrix was further developed and used during the establishment of the Ethiopia Kaizen Institute.

Quantitative and qualitative assessment criteria, ${ }^{1}$ as shown in Table 5.1, were designed to determine the effects of Kaizen activities on companies. The impact of Kaizen on 28 out of 30 companies was assessed using the above assessment criteria and the results are summarized in Table 5.2. The pilot project raised quality and productivity consciousness in the pilot companies. It was clear that introducing Kaizen into these companies improved quality, productivity, and safety, reducing costs and lead time.

Those companies with Grade III and above, which constitute 65\% of the total population, are characterized by strong management commitment and good management-employee relationships, while those below Grade III that accounts for 35\% lack these commitments. The impact of Kaizen activity on $65 \%$ of the companies constitutes satisfactory achievement, thereby confirming the success of the project. In addition, this result indicates the high transferability and high acceptability of Kaizen to Ethiopian companies.

The second objective of the project was to develop a manual to be used by KU members and the proposed Ethiopia Kaizen Institute, which was under consideration by the government at that time. The manual contains procedures, steps, and a sequential flow of Kaizen activities. The

\footnotetext{
${ }^{1}$ Kaizen results are counted on two levels. The first level consists of qualitative results such as changes in attitude, improvement of industrial culture, and improvements in work relations between management and employees. The second one comprises quantitative results calculated before Kaizen activity implementation to set targets and after implementation to observe the changes. Usually calculations are based on Kaizen elements (quality, productivity, cost, delivery, safety, environment, and morals).
} 
Table 5.1 Assessment criteria

\begin{tabular}{|c|c|c|c|c|}
\hline \multicolumn{2}{|c|}{ Area } & $\begin{array}{l}\text { Indicator } \\
\begin{array}{l}(1-1) \text { defect } \\
\text { rate }\end{array}\end{array}$ & $\begin{array}{l}\text { Formula } \\
\text { (Quantity of defects)/ } \\
\text { (quantity of product } \\
\text { produced) }\end{array}$ & \multirow{2}{*}{$\begin{array}{l}\text { Data required and } \\
\text { other notes } \\
\text { Either one of the two } \\
\text { should be used } \\
\text { depending on the } \\
\text { nature of production } \\
\text { process }\end{array}$} \\
\hline & Quality & $\begin{array}{l}(1-1) \text { defect } \\
\text { rate }\end{array}$ & $\begin{array}{l}\text { (Quantity of defects)/ } \\
\text { (quantity of product } \\
\text { produced) } \\
\text { (Quantity of good } \\
\text { products produced)/ } \\
\text { (quantity of } \\
\text { material input) }\end{array}$ & \\
\hline \multirow[t]{2}{*}{2.} & Cost & $\begin{array}{l}(2-1) \text { cost by } \\
\text { product }\end{array}$ & $\begin{array}{l}\text { Cost by product per } \\
\text { unit }\end{array}$ & \\
\hline & & $\begin{array}{l}(2-2) \text { gross } \\
\text { profit ratio }\end{array}$ & $\begin{array}{l}\text { (Revenue - cost of } \\
\text { goods sold)/ } \\
\text { (revenue) }\end{array}$ & $\begin{array}{l}\text { Gross profit ratios by } \\
\text { product, as well as } \\
\text { total company }\end{array}$ \\
\hline 3. & Delivery & $\begin{array}{l}\text { (3-1) delivery } \\
\text { schedule } \\
\text { non- } \\
\text { adherence } \\
\text { count }\end{array}$ & $\begin{array}{l}\text { Number of occurrence } \\
\text { of delivery schedule } \\
\text { non-adherence }\end{array}$ & $\begin{array}{l}\text { Associated records: } \\
\text { description including } \\
\text { reason/background of } \\
\text { each non-adherence } \\
\text { case }\end{array}$ \\
\hline & Safety & $\begin{array}{l}(4-1) \text { labor } \\
\text { injury } \\
\text { count }\end{array}$ & $\begin{array}{l}\text { Number of labor } \\
\text { injuries }\end{array}$ & $\begin{array}{l}\text { Associated records: } \\
\text { description of } \\
\text { incidence including } \\
\text { reason/background }\end{array}$ \\
\hline \multirow[t]{2}{*}{5.} & Productivity & $\begin{array}{l}(5-1) \\
\text { machine } \\
\text { utilization } \\
\text { rate }\end{array}$ & $\begin{array}{l}\text { (Actual time machine } \\
\text { utilized)/(planned } \\
\text { machine utilization } \\
\text { time) }\end{array}$ & $\begin{array}{l}\text { Associated records: time/ } \\
\text { duration and reason } \\
\text { for each facility } \\
\text { stoppage occurrence }\end{array}$ \\
\hline & & $\begin{array}{l}(5-2) \\
\text { production } \\
\text { capacity }\end{array}$ & $\begin{array}{l}\text { Quantity of products } \\
\text { produced per unit } \\
\text { time }\end{array}$ & \\
\hline & Morale & $\begin{array}{l}(6-1) \\
\text { absentee } \\
\text { ratio }\end{array}$ & $\begin{array}{l}\text { (Number of absent } \\
\text { employees)/(total } \\
\text { number of } \\
\text { employees) }\end{array}$ & (HR data) \\
\hline
\end{tabular}

Source: JICA (2011a)

Table 5.2 Assessment results of pilot companies

\begin{tabular}{lllllll}
\hline & \multicolumn{3}{l}{ Grade } & & \\
\cline { 2 - 5 } Sub-sector & 1 & 2 & 3 & 4 & 5 & Total number of companies \\
\hline 1. Metal & 1 & 2 & 2 & 2 & 1 & 8 \\
2. Textile & 1 & 1 & 1 & 1 & 1 & 5 \\
3. Agro & 1 & 2 & 1 & 1 & 1 & 6 \\
4. Chemical & & 1 & 2 & & 3 & 6 \\
5. Leather & 1 & & 2 & & & 3 \\
Total & 4 & 6 & 8 & 4 & 6 & 28 \\
\hline
\end{tabular}

Source: JICA (2011a) 
sequence primarily consists of (1) acquisition of Kaizen knowledge, (2) rapid assessment of the workplace environment and operations at companies for identification of problems, (3) selection of model workplaces, (4) application of Kaizen activities at selected model workplaces for examination, (5) self-organization of Kaizen activities through conducting QCC activities, (6) preparatory work for companywide Kaizen activities, and (7) self-evaluation of Kaizen activities for continual Kaizen dissemination. This sequential flow comprises an actual application of PDCA modality (i.e., 'Plan-Do-Check-Act' cycle). Thus, the manual provides not only the operational and procedural guides for carrying out Kaizen activities but also enhances opportunities to customize the application methodology revealed in the manual into various workplaces and companies. The manual is accompanied by audio-visual ${ }^{2}$ materials.

The Kaizen knowledge components and the steps moving from the base to the top with the help of PDCA cycle were depicted as a Kaizen tree to clearly show the Kaizen system in action in five sequential steps from simple to complex. This concept has been used in crafting the Ethiopia Kaizen Model and Roadmap, which will be discussed in Section 5.3.

The third objective of the pilot project was to develop a National Plan, which was comprised of objectives and strategies for dissemination, institutionalization, and establishment of a Kaizen movement. However, the latter two were not covered by the project. JICA recruited additional experts to undertake an institutionalization study. The study of the Kaizen movement and extraction of best experiences relevant to Ethiopia was done as part of the High level Policy Dialogue.

The dissemination plan was incorporated into the manual. The Kaizen dissemination plan took into consideration synchronizing the implementation of Kaizen with the National Development Plan. During the final stage of the project, Ethiopia was crafting the Growth and Transformation Plan (GTP I) and revising the Micro and Small Enterprise Development Strategy. It was an opportunity to streamline Kaizen dissemination into the national plan and to formulate the modalities for reaching various scales of companies.

\footnotetext{
${ }^{2}$ The audio-visual materials are DVDs elaborating Kaizen components using simulations by KU members. They show company experiences of customizing Kaizen activities to Ethiopian situations and interviews.
} 
The awareness and quick decision to adopt Kaizen by the government of Ethiopia, the rapid response by JICA in designing the project and deploying experts, and the success of the project became a landmark for subsequent JICA assistance and the benefits were harnessed by Ethiopian companies. It provided the impetus for the Ethiopian government to establish a strong and vibrant Kaizen Institute, thereby nurturing hundreds of Kaizen consultants and making Ethiopia Kaizen a flagship project for JICA. As a landmark, it contributed to the upgrading of KU into the Ethiopia Kaizen Institute, where it could craft its vision as "a center for transformed working cultures and innovation management skill," thus spearheading its place as a center of excellence in Africa.

\subsection{Institutional Development}

The remarkable success of the pilot project increased the Ethiopian appetite for knowledge. During the wind-up of the pilot project, the Ethiopian government, delighted with the results and setting its sights on establishing the Ethiopia Kaizen Institute, and incorporating KU members as its core staff, requested that JICA undertake a study of the institutionalization framework. JICA was also satisfied with the performance of the project and was ready to help. KU members had been introduced to Kaizen and had recognized its potential. The objective of the study of institutionalization was mainly to draw lessons from different countries assisted by Kaizen. An expert in the field who participated in the Singapore JICA Quality and Productivity Project was appointed. Sato (2011) explored the experiences of 13 countries in different regions: in Asia (Singapore, Malaysia, Thailand, and Vietnam), Latin American (Chile, Argentina, and Mexico), and Eastern Europe (Poland, Baltic countries, Armenia, Bosnia and Herzegovina, and Serbia).

The experiences of these countries have been summarized below in a way that shows how key insights were helpful in establishing an institute that met the needs of Ethiopia. During the study, there were frequent discussions with the experts and the conclusion we arrived at was that many things could be learned from both the success and failure cases of other countries. 


\subsubsection{Learning from Success Factors}

\subsubsection{Approach to Kaizen Activities}

Most of the countries included in the study tried to implement Kaizen activities at the level of a national movement; however, only Asian countries were able to successfully realize the approach. A major factor identified for success is the commitment of political leadership. For instance, in Singapore, the Prime Minister undertook initiatives toward promoting Kaizen activities. Top management commitment was not limited only to political leadership but also applied to enterprises and institutions involved in disseminating Kaizen.

\subsubsection{Vision, Mission, and Objectives}

Those countries that promoted their own quality and productivity movements and succeeded have crafted their own visions, missions, and objectives suitable to their specific conditions. This is very important because no two countries are alike in every aspect.

\subsubsection{Organizational Frameworks}

The experiences of each country show that there is no blueprint or standard organizational framework. In most cases, it depends on political will, as well as the policy and strategy environment within each country the institution is intended to serve. The experiences of different countries show that they have different institutional set-ups, commonly known as organizational structures. Some organizational structures are simple while others are complex. Although, in most of the studied cases, governments use the same name, 'productivity center', to describe the institution, the functional structure, the courses delivered, the scope of activities, and target groups served differ. 


\subsubsection{Importance of Customization}

The experience of countries covered by the study showed that some countries failed to persevere, while others succeed. The difference between success and failure depends, by and large, on materials' development for training and consultancy services. In most cases, those countries that did not make good progress were those using teaching materials they had obtained from other countries without any modifications. Those who succeeded expanded implementation in their own countries and even abroad. Some modified teaching materials and developed certification bodies to match their own needs. To achieve the need of a country, customizing teaching materials, methods, and ways of dissemination must receive the attention of local staff. It could be said that preparing custommade teaching materials is a key factor in successful activities.

\subsubsection{Creating a Kaizen Mindset}

As discussed in Chap. 1, continuous improvement is one of the principles of Kaizen. However, normally, people tend toward keeping the status quo and maintaining prevailing conditions without change. This is mainly due to comfortable familiarity with existing circumstances, fear of the unknown, and desire to preserve a peaceful life. Kaizen activities cannot be implemented with such an attitude. Changes in attitudes or receptiveness to new ideas for improvement are a result of basic Kaizen and a prerequisite for advanced Kaizen and further progress. The case studies showed how experts faced enormous challenges in changing people's mindsets in some countries.

\subsubsection{The Need for Commitment and Leadership}

As has repeatedly been noted, the commitment of top management is the most crucial element in the success of Kaizen activities. No success has been made without commitment from top management. For instance, in the case of Singapore, the success of their quality and productivity movement was the outcome of the commitment of Prime Minister Lee Kuan 
Yew. In Japan, the success of Kaizen activities depends entirely on the commitment of institutions like the Japan Productivity Centre, Japan Union of Scientists and Engineers, Japan Management Association, and companies' top management. It can be concluded that success is the result of top-level commitments at all levels. Leaving Kaizen activities entirely to foreign experts is unlikely to bring about the desired results. The participation of local staff in all activities and taking on leadership to meet local needs is very crucial.

\subsubsection{Expanding Kaizen Activities}

The experience of some successful countries shows that they were trying to extend their activities to other countries. Some were trying to become centers of Kaizen activities in their region. This indicates that success could create opportunities to excel and become a center of excellence, thus broadening Kaizen activities beyond their own borders.

\subsubsection{Learning from Cases of Failure}

One can learn not only from success factors but also from cases of failure as well. Factors contributing to failure, among other things, are implementing Kaizen only to meet short-term goals, leaving Kaizen activities to foreign experts, and not being sufficiently involved from the beginning, thereby creating gaps after the experts have left. Using a 'copy-andpaste' approach or depending exclusively on foreign-made teaching materials without customizing these to meet local needs, lack of a clear vision, mission, and strategy are also major factors leading to failure in some countries.

These successes and failure cases were taken as an input while designing the organizational structure of the Ethiopia Kaizen Institute and crafting strategies to successfully transfer and develop Kaizen in Ethiopia. One important concept of institutional development is human-oriented management. This concept is unique compared to others developed in Western countries. In Japan, it is common for top management to encourage employee improvement. There is a saying, "if you do not have 
money, you need to use your brain, and if you do not have a brain, you should make your maximum effort through toil at your work". The literal meaning of this saying is to make work improvements without spending money or by investing time (without using money).

\subsubsection{The Ethiopia Kaizen Institute}

Taking into account the dissemination plan prepared by the project (JICA 2011b) and lessons learned from the experience of other countries (Sato 2011), a Formation Paper explaining (1) the concept of Kaizen, (2) the experiences of successful countries including Japan and Singapore, (3) the achievements of the pilot project, (4) the survey of the positive response of participants in the discussion on the institutional development study, (5) the role of the institute, and (6) the scope of its activity in launching a countrywide movement as well as the Gazette were prepared by KU and presented to the Council of Ministers for a decision. The Ethiopia Kaizen Institute was established by the proclamation of the Council of Ministers 256/2011 (FDRE 2011). The objectives of the institute as stipulated in the gazette are to initiate a countrywide broad-based quality and productivity movement and thereby enhance industry competitiveness. The major powers and duties of the institute are as follows:

1. formulate and implement as approved; policies, strategies and programs that assist in the dissemination of the Kaizen knowledge and implementation tools, create a countrywide quality and productivity movement that could enable the effective implementation of government policies and strategies;

2. prepare, review, and distribute Kaizen training and consultancy manuals customized to micro, small, medium, and large enterprises and follow up their performances; provide training of trainers on Technical and Vocational Education and Training Institutes' industrial extension experts to enable them to be capable to provide Kaizen training and consultancy to micro and small enterprises and provide Kaizen training and consultancy to medium and large companies; 
3. coordinate, consult, and support Kaizen concepts and tools to disseminate them at any level of service and educational institutes, establish and perform a system that induces organizations to implement Kaizen, support organizations to establish quality control circles and/ or continuous improvement circles, and register their performances;

4. conduct studies, collect, organize, and disseminate information to observe improvements made because of Kaizen; prepare key performance indicators to measure Kaizen implementation results, establish evaluation and certification systems for Kaizen trainers and consultants, accumulate best Kaizen practices, disseminate and produce Kaizen model companies; and

5. prepare recognition and incentive systems and implement them upon approval of organizations; recognize quality control circles that have excelled in Kaizen training and consultancy performances; designate a quality month and perform countrywide discussion forums.

The institute is presently accountable to the Ministry of Public Service and Human Resource Development. The Joint Coordination Committee of the JICA project is chaired by the Minister. The institute submits to the ministry monthly, quarterly, and annual performance reports and is evaluated by the management team of the ministry chaired by the minister. The leadership tier consists of a council, ministry, director general, and deputy director generals. The Prime Minister is the Chairperson of the Council and members are drawn from appropriate government offices, the private sector, and professional associations. The number of members is determined as required. The duties of the council are mainly to:

1. advise the institute on its activities;

2. evaluate and forward its recommendations on Kaizen strategies, plans, studies, and research formulated with a view to facilitating the development of manufacturing and service-rendering organizations;

3. forward its opinions on capacity-building programs; and

4. evaluate the implementation of the plans of the Institute. 
JICA commissioned the second project to train Kaizen consultants recruited by the institute. The project duration was for three years from November 2011 to December 2014. The outputs of the project were:

1. The institutional and organizational foundation of Ethiopia Kaizen Institute (EKI) is established as the core and lead organization for the dissemination of quality and productivity improvement, that is, Kaizen;

2. The system of HRD for dissemination of quality and productivity improvements to large and medium enterprises is functionalized in EKI; and

3. The model system for EKI to foster TVET trainers' trainers (TTTs) is developed for quality and productivity improvement (Kaizen) for micro and small enterprises (MSEs) (JICA 2014a).

JICA deployed an expert group and EKI continuously recruited consultants to be trained by the project. Six consultants who were former KU members were permanently attached to the project. The modalities of training were one-month classroom training (CRT) and five-month incompany training (ICT) for medium and large industries and two-week CRT and eight-week ICT for micro and small enterprises. The Japanese experts provided classroom trainings to EKI consultants and to TVET trainers of trainers. TVET trainers of trainers were selected from all regions and they were expected to expand Kaizen activities in their respective regions. In each batch, large and medium enterprises as well as micro and small enterprises were selected. The selection was followed by a reconnaissance survey by JICA and EKI consultants. Based on the survey results and commitments of the company, a one-day awareness creation program was conducted mainly for managers and Kaizen representatives to further stimulate their motivation. EKI consultants were deployed to enterprises supervised and assisted by JICA experts.

The project plan called for the training of 60 EKI consultants over three years of the project, while the actual achievement was 57 trained consultants. The difference was mainly due to EKI's limited capacity to supply trainees as per the plan in each batch. The plan also called for the training of 170 professional TVET trainers, with 137 TVET trainers' trainers actually achieved. The difference of 33 TVET trainers was due to 
the failure of some regions to send a satisfactory number to EKI for the training in each batch. This problem was observed at a later stage and the reason was that the newly trained TVET trainers' trainers were leaving their respective institutions and regions because they were offered better salaries when they returned with their certificates showing they had completed Kaizen training. The issuing of such certificates became a problem and was discussed among JICA experts and EKI. Through in-company training, Kaizen was introduced to 51 large and medium enterprises and 129 micro and small enterprises.

The consultant training program was comprised of two parts. In addition to the training in Ethiopia discussed above, ten top management members and those consultants attached to the project were trained in Japan. A further 36 consultants received training in Malaysia. As part of the strengthening of the institute, 3 vehicles, 1 big copy machine, 8 projectors, 11 notebook personal computers, and 6 video cameras were provided to EKI through the project.

During the final stage of the project, training materials and the supporting manual (JICA 2014b) were developed to be used by EKI after the project. The manual consists of two volumes, with volume one comprising the various concepts and principles of Kaizen technologies with detailed explanations, while volume two deals with practical examples of how to use each technique. In addition to these, a manual on best practices of QCCs in Japan was prepared by Professor Hiroshi Osada (Professor Emeritus of Tokyo Institute of Technology) at the request of EKI to provide more information about QCC activities and problemsolving methodologies. The request was accepted by JICA and a manual consisting of 12 cases of best practice on quality control circles-originally published in Japanese language by Union of Japanese Scientists and Engineers (JUSE) — was translated and published (Osada 2013).

The number of consultants increased during the course of the second project. When the project started in 2014 , the institute was staffed by 123 employees, with 82 consultants ( 44 male and 38 female). Out of this total, 57 were trained by the project. As of 2017, the institute has 153 employees including 107 consultants-65 males and 42 females-an increase of 30\% within two years. A comparison between 2014 and 2016 is given in Table 5.3. 
Table 5.3 Growth of consultants from 2014 to 2017 at EKI

\begin{tabular}{|c|c|c|c|c|c|c|c|}
\hline \multirow[b]{2}{*}{ S.N. } & \multirow[b]{2}{*}{ Job title } & \multicolumn{3}{|c|}{2014} & \multicolumn{3}{|c|}{2017} \\
\hline & & $\mathrm{M}$ & $\mathrm{F}$ & $\mathrm{T}$ & $M$ & $\mathrm{~F}$ & $\mathrm{~T}$ \\
\hline 1 & Director General & 1 & - & 1 & 1 & - & 1 \\
\hline 2 & Deputy Director General & 1 & - & 1 & 2 & 1 & 3 \\
\hline 3 & Director & 4 & 3 & 7 & 8 & 3 & 11 \\
\hline 4 & Lead Consultant & 4 & 0 & 4 & 7 & 1 & 8 \\
\hline 5 & Senior Consultant & 5 & 1 & 6 & 22 & 7 & 29 \\
\hline 6 & Consultant & 3 & 1 & 4 & 7 & 2 & 9 \\
\hline 7 & Associate Consultant & 12 & 23 & 35 & 8 & 19 & 27 \\
\hline 8 & Junior Consultant & 15 & 9 & 24 & 10 & 9 & 19 \\
\hline Total & & 44 & 38 & 82 & 65 & 42 & 107 \\
\hline
\end{tabular}

Source: Compiled from EKI data (2016c)

Note: S.N. serial number, $M$ male, $F$ female, $T$ total

The second project was considered to be success and the JICA evaluation report concluded that its achievements were satisfactory. With EKI growing in strength over time, a request was placed for JICA for a third assistance project. The goal of the assistance is for intermediate Kaizen capacity building based on the long-term strategy proposed in the report and in the framework of the Second Growth and Transformational Plan. Kaizen is well reflected in this plan and EKI has designed its own fiveyear plan corresponding to the GTP II period 2015-2020 (FDRE 2015). The request was accepted, and it is expected that 90 consultants will be trained in intermediate Kaizen with the help of this project. The organizational structure of the institute has been changed twice within a fouryear period. The major cause of the change is the expansion of EKI's activities. The current structure is organized around 5 major sectors and 21 Directorates (EKI 2016a) as indicated in Fig. 5.1.

The change was not only in structure but also in motivating the consultants by raising their salaries and providing benefits. For comparison, Table 5.4 shows the original and current job grades, salary scale and benefits (gross pay before tax deduction in terms of nominal income) and percentage changes. The changes in payroll for different job grades are about $32 \%$ on the lower side and $41 \%$ on the higher side.

EKI's recruitment policy is to employ young graduates from universities with high grades, train them in-house for six to ten months on the theory and practice of Kaizen (CRT and ICT), and deploy them to provide 


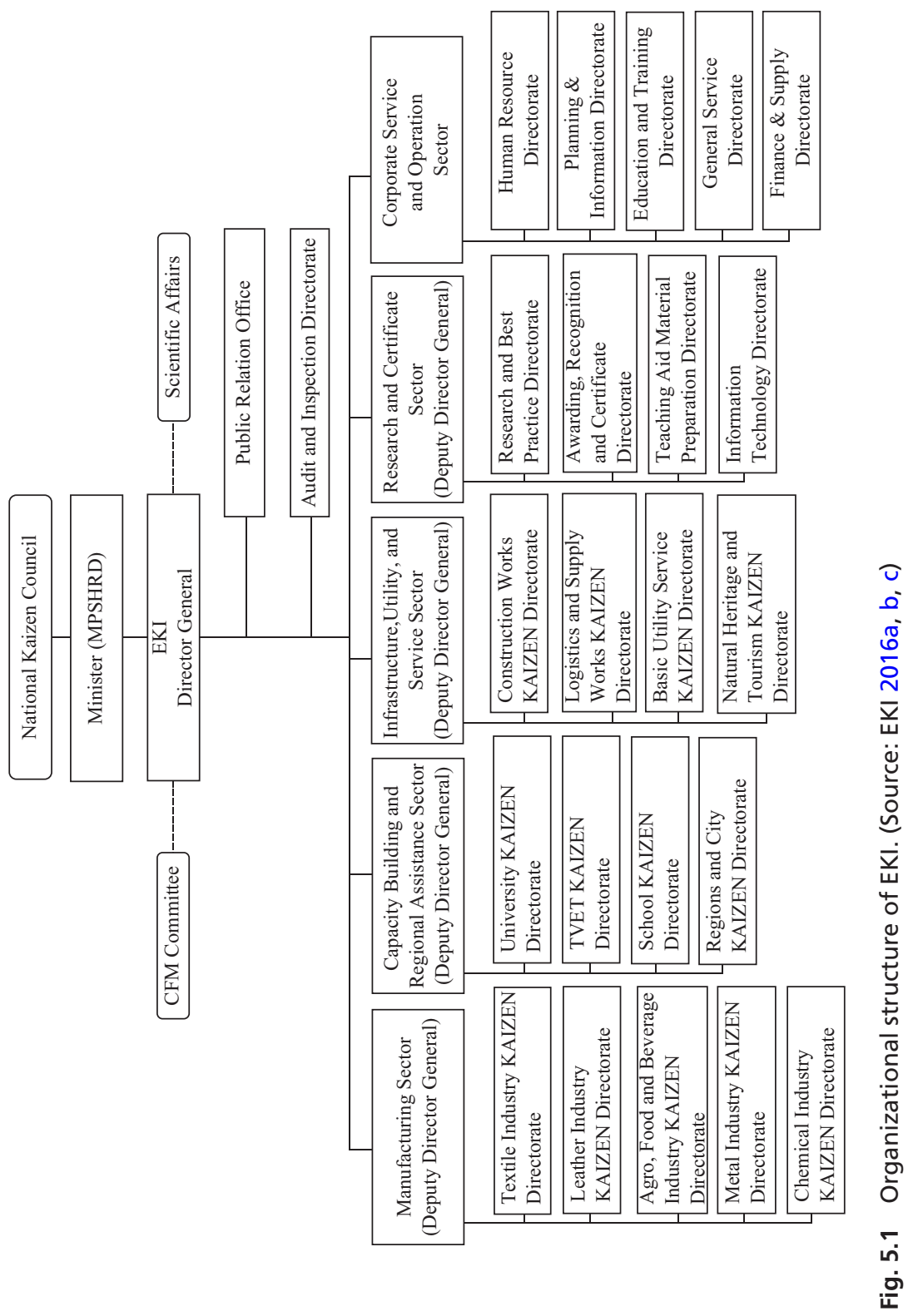



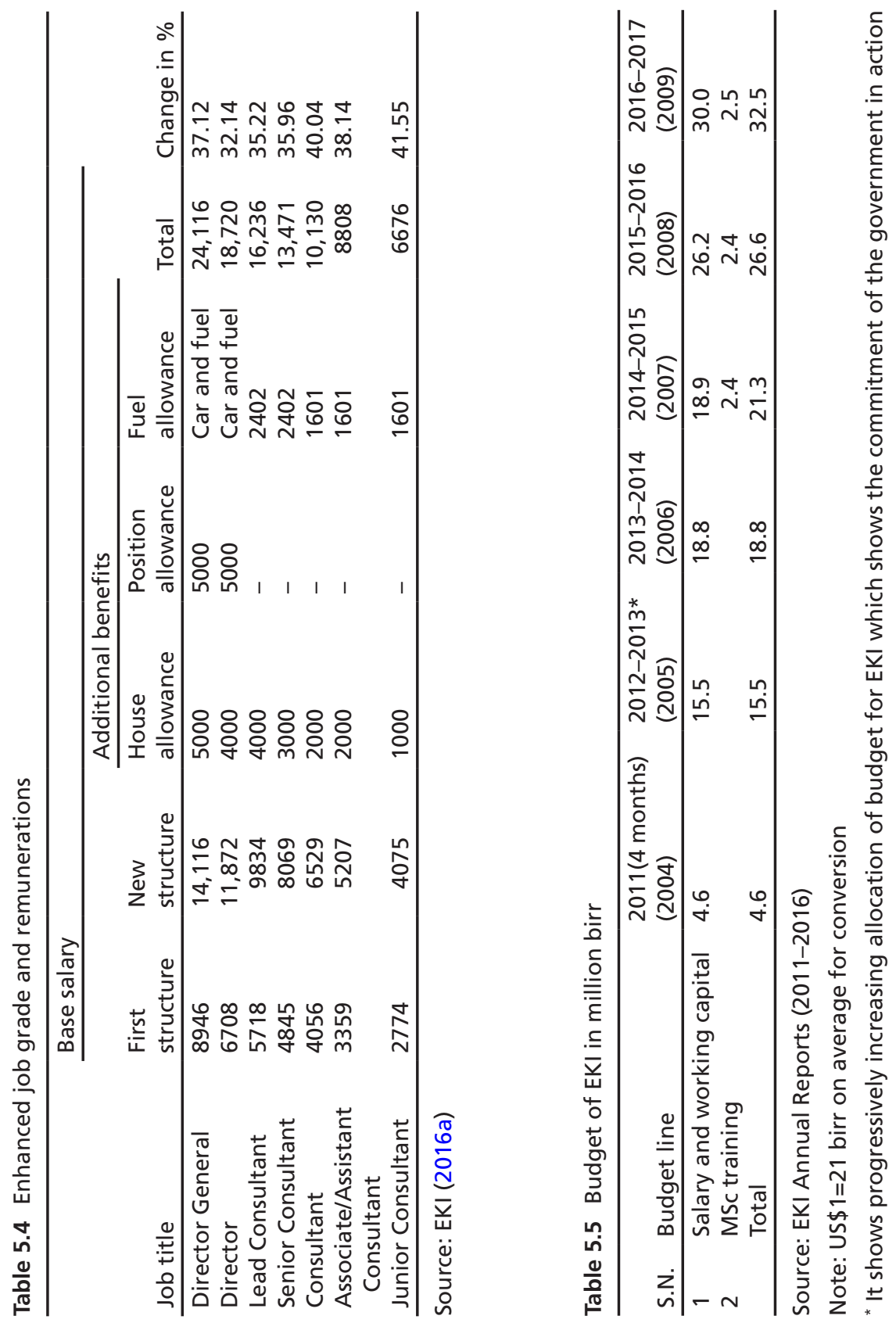
support for the movement. At the management level, EKI employs senior people by following stringent selection procedures. Ensuring gender balance is an important consideration because in the textile, leather, and food areas, by and large, the proportion of females is very high, and gender mainstreaming is a development policy of the Ethiopian government.

Creating a strong and vibrant institute cannot happen without the required resources, particularly finance. The Government of Ethiopia showed its commitment right from the beginning. EKI was established in the fourth quarter according to the Ethiopian calendar. The fourth quarter is usually time for clearing backlogs, not a time to request new budgetary allocations. However, the government allocated 4.6 million birr for four months to start up the institute. So far, the budget has never been a limiting factor for its activities. From 2014/2015 onwards, the government allocated budget to provide not only working capital but also money for local training for MSc degrees in Kaizen. Table 5.5 indicates the growth of the EKI budget over time in nominal values.

In summary, the first project confirmed the transferability of Kaizen to Ethiopia and led to the birth of EKI. The second project trained $57 \mathrm{EKI}$ consultants and helped EKI to develop autonomous capacity for launching a Kaizen movement using basic Kaizen knowledge without the help of Japanese experts or other foreign assistance. The third project is to raise the capacity of EKI to an intermediate level (JICA 2016). By the end of this project, EKI hopes to achieve an advanced level of Kaizen, which is the apex of Kaizen knowledge. It has planned for this venture to be undertaken in the years 2020-2025.

\subsection{Ethiopian Kaizen: Roadmap and Strategies}

At the end of the pilot project, KU raised questions concerning the scope of Kaizen knowledge and how quickly we would be able to learn. The more we discussed Kaizen with the JICA experts and the more we read literature on matters related to Kaizen, the more we came to understand the difficulties involved in learning and applying all of the concepts and technologies in a short period of time. In response to this difficulty, the JICA team developed the Kaizen tree concepts, articulated in Chap. 1. 
The tree approach stratifies Kaizen knowledge into five layers (JICA 2011a). KU members were given an overview of Kaizen and exposed to knowledge on 5S, standard operations, QCC, and MUDA. Complex concepts and systems such as total quality management (TQM), total productive maintenance (TPM), and analytical tools such as 7QC tools and basic industrial engineering (IEs) were introduced briefly at the end of the project to provide participants with a very basic awareness of the terms. During the first and second round of classroom sessions and the company trainings of the second project, the challenges this posed for participants became obvious. There was enormous complexity in high-level concepts such as TQM (Umeda 2001), TPM (Suzuki 1994), policy deployment, process capability, quality diagnosis, cost management, delivery management, Toyota Production System (TPS) (Liker 2004; Kato and Smalley 2011), the whole system, and the methods of the problem-solving approach (Hosotani 1989). This prompted us to recall the lessons that we had drawn from the experiences of other countries: not to leave everything to foreign experts and the need to customize Kaizen knowledge, training materials, and dissemination methodology to the local context. We started thinking about how to develop a roadmap and strategy of our own-the Ethiopian way. In particular, the sharing of the history of QCC development in Japan in three stages - that is, junior, medium, and high levelopened our eyes and unlocked our potential to generate ideas on how to categorize Kaizen into different levels ranging from simple to complex.

From the readings of various books written on Kaizen, EKI has borrowed from the ideas of Masaaki Imai (1986), who described Kaizen as “...the unifying thread running through the philosophy, the systems, and the problem-solving tools developed in Japan over the last 30 years". The 30 years Imai refers to run from the 1950 s to the 1980 s, a period when Japanese people vowed to learn Western scientific management and quality control. They also customized, improved, and developed new concepts, systems, and tools. A comprehensive definition of Kaizen is given in Chap. 1.

After collecting the training course materials in the pilot and second projects, EKI assembled them into three components (management/ principles, systems, tools) according to the difficulty of learning and implementation in companies. The idea of classifying Kaizen into three levels was presented for discussion to EKI staff and JICA experts. This was incorporated into Kaizen overview training courses by EKI consultants 
and continuously improved based on feedback collected from companies and consultants.

EKI top management produced a paper, the Kaizen Movement Strategic Directions and Action Plan from 2015 to 2025 (EKI 2014a), which was circulated among JICA Tokyo and JICA Ethiopia, GRIPS Development Forum, Policy Dialogue Forum members in Ethiopia, ministries, JICA project experts, and institutions established to assist different industrial sub-sectors. The paper has two parts, with the first part providing a historical overview and definition of Kaizen, offering a brief review of the introduction of Kaizen to Ethiopia, and discussing the customized approach of Ethiopian Kaizen and Kaizen infrastructure-that is, how to structure Kaizen institutions nationwide.

Part two of the paper presents the long-term action plan, mission and vision, goals, objectives and actions, resources required, and major support programs. The action plan details major activities during 2012-2025 in three stages, with each stage to be completed in five years. The plan also articulates the desired outcomes of consultant development at different levels, the impacts of Kaizen dissemination in improving quality and productivity and enhancing the competitiveness of companies, as well as the resources and technical support required. Japanese experience shows the importance of the strategic involvement of their scholars, organized under Japan Union of Scientists and Engineers and Japan Management Association, in developing improved and new tools, manuals, and procedures. In recognition of this fact, and seeking to lay the foundations for the creation of local capacity to enhance the conceptual and analytical capability of consultants and creating linkage with universities, EKI initiated MSc and PhD programs on Kaizen in 2014.

As part of the local customization effort, three books have been written in local languages ${ }^{3}$ (Mekonen 2014, 2015a, 2017). The first book discusses the four steps of Kaizen transfer and ownership modality. The first three steps refer to the transfer of Kaizen from the source, Japan, to Ethiopia over the next 13 years (2012-2025). The year 2025 is the deadline set by the government for transforming Ethiopia from a low middleincome country and EKI therefore also set this year as the target for

\footnotetext{
${ }^{3}$ These three books are written by the author of this chapter, who is the former Director General of EKI.
} 
completing the transfer of Kaizen. The fourth step is ownership of total Kaizen, customizing it to the Ethiopian situation and crafting an Ethiopian management version. This book fostered discussions within EKI and the public, and the feedback was encouraging.

The second book explores the Toyota way from three perspectiveslean management, lean leadership, and lean manufacturing-and extracts lessons relevant to the Ethiopian situation in a simplified way. The third book comprises a simplified approach to integrating TQM, TPM, and TPS principles and draws up a framework on how to synchronize and implement them. Several MSc papers and studies were conducted on different aspects of Kaizen by different universities. In addition, 18 MSc papers were produced by the first graduates of MSc on Kaizen by EKI consultants. EKI has also produced a Kaizen song emphasizing the importance of quality and productivity improvement, along with the resulting benefits, citing the results of Kaizen implementation as examples. This song has been broadcast on various public and private media outlets, most often in the month of September (the Kaizen month).

EKI top management produced a paper, the "Comprehensive Understanding of Kaizen and Implementation Strategy" (EKI 2014b), which primarily focused on creating a common language, the components of the three levels, the three development stages of Kaizen promotion teams (KPTs) ${ }^{4}$ equivalent to QCCs (JUSE 1985), and the role of industrial development institutes in disseminating Kaizen. This paper was circulated among different institutions and finally became a government policy.

Although the roadmap for transferring Kaizen over a 15-year period in three stages and the direction set is doable, EKI felt that its knowledge of Kaizen was still incomplete. One morning in July 2014, EKI top management asked if one of the JICA experts, namely Mr. Seiji Sugimoto, could provide a complete list of Kaizen concepts, systems, and tools. After two days, he came up with a list of 82 elements or courses of Kaizen on A-3 paper-some of which were unheard of within EKI. After some discussion about the list, he was requested to categorize them into the three levels of components EKI had generated previously. Simple criteria

\footnotetext{
${ }^{4} \mathrm{KPT}$ s are a customized approach to QCCs, the $5 \mathrm{~S}$ committee, TQM committee, SOP committee, and TPM committee, by which the activities of all these committees are undertaken from within the same KPTs organizational structure step by step.
} 
were developed for differentiating these concepts into levels based on the difficulty of learning and the ability of consultants and companies, given their absorptive capability, to comprehend the terms. Finally, with the help of Professor Hiroshi Osada, the Strategic Framework of Ethiopia Kaizen Version One was crafted (EKI 2014c). From this framework, the Ethiopia Kaizen Model was designed. The model comprises a three-levelknowledge, three-level-qualification, three-level-organization, and threeterm-transfer model.

Three-level knowledge refers to the categorization of Kaizen into three stages, depending on learning and implementing complexity. Three-level qualifications indicate that the professional requirement for the first level is $\mathrm{BSc} / \mathrm{BA}$, the second level MSc/MA and the third level is a $\mathrm{PhD}$ in Kaizen management. Three-level organizations refer to EKI at the federal level, regional Kaizen institutes, and Kaizen units organized in Kaizen implementing organizations, and the synergy between them. Three-term transfer is the time that it took Ethiopia to complete the knowledge transfer of and 'own' Kaizen. The first term occurred between 2012 and 2014, whereby the first level was transferred, and this has thus been achieved. The second term is from 2015 to 2020, with the goal of transferring and owning the second level of Kaizen with the assistance of JICA through the third project for the same period. The third term will be from 2020 to 2025, as per the strategic framework of Ethiopian Kaizen. The components of Kaizen that apply to each level are also defined (see Tables 5.6, 5.7, and 5.8).

Level one (Table 5.6) consists of basic Kaizen, which can be managed by first degree holders and junior KPTs (junior QCCs). As indicated above, EKI is capable enough of training its newly recruited consultants as part of internal consultancy development and also of providing training and consultancy to companies, without the assistance of foreign experts.

Level two (Table 5.7) is relatively advanced compared to level one. This level can be handled by second degree holders or highly experienced consultants and medium KPTs (medium QCCs). As discussed above, this level is planned to be attained between 2015 and 2020.

There might be some overlaps of concepts and technologies within the levels depending on the absorptive capabilities of implementing companies and, whenever such conditions emerge, the consultants can adjust to the situation. Each one of these levels passes through 5 steps and 20 
Table 5.6 First-level Kaizen

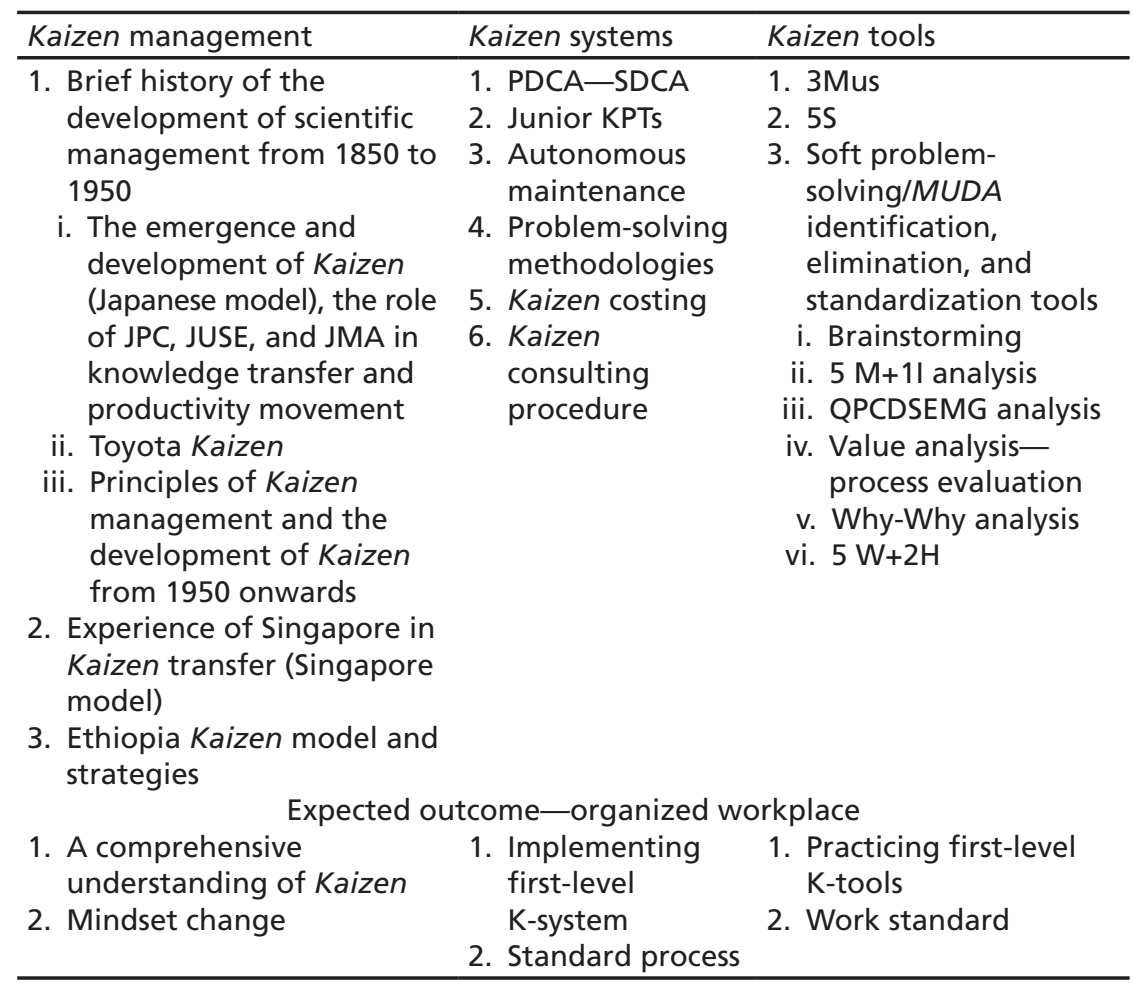

Source: EKI (2014c)

major activities known as the TIISO Model (Mekonen 2017). TIISO stands for testing, institutionalizing, implementing, sustaining, and ownership. Testing refers to the learning and trial period of any new concepts and technologies. Institutionalization is customizing the curriculum and teaching materials and producing capable consultants. Implementation refers to the widening and deepening of dissemination activities in companies. Sustaining is making a brake not to slide back, while standardization and ownership refer to the complete transfer of the concepts, technologies, and management without foreign assistance. The TIISO Model is presented in Figs. 5.2 and 5.3.

Detailed activities need to be performed for each step. For instance, testing has two activities: learning from abroad—that is, Japan—and building local capability. The rest are indicated in Fig. 5.3. 
Table 5.7 Second-level Kaizen

\begin{tabular}{|c|c|c|}
\hline Kaizen management & Kaizen system & Kaizen tools \\
\hline $\begin{array}{l}\text { 1. Kaizen management } \\
\text { i. Productivity } \\
\text { management } \\
\text { ii. Quality } \\
\text { management } \\
\text { iii. Cost management } \\
\text { iv. Delivery } \\
\text { management } \\
\text { v. Policy management } \\
\text { vi. Cross-functional } \\
\text { management } \\
\text { vii. Daily management } \\
\text { 2. Basics of Kaizen } \\
\text { leadership-lean } \\
\text { leadership }\end{array}$ & $\begin{array}{l}\text { 1. Medium KPTs } \\
\text { 2. TPS } \\
\text { 3. Intermediate TQM } \\
\text { 4. Intermediate TPM } \\
\text { 5. Appropriate costing } \\
\text { system } \\
\text { 6. MRP } \\
\text { 7. Production } \\
\text { scheduling }\end{array}$ & $\begin{array}{l}\text { 1. SOP } \\
\text { 2. } 7 \text { QC tools/QC story } \\
\text { 3. Value stream mapping } \\
\text { 4. Quality control process } \\
\text { chart } \\
\text { 5. Basic IEs } \\
\text { Time study } \\
\text { Motion study } \\
\text { Line balancing } \\
\text { Process analysis } \\
\text { Operation analysis } \\
\text { Control charts } \\
\text { Process capability index } \\
\text { Ergonomics } \\
\text { Layout } \\
\text { 6. Multi-activity analysis } \\
\text { 7. Ratio-delay study } \\
\text { 8. Shortening set-up time }\end{array}$ \\
\hline $\begin{array}{l}\text { 1. A comprehensive } \\
\text { understanding of } \\
\text { intermediate Kaizen } \\
\text { management } \\
\text { 2. Strategic leadership }\end{array}$ & $\begin{array}{l}\text { ted outcome-system } \\
\text { 1. Implementing } \\
\text { second-level } \\
\text { K-system } \\
\text { 2. Standard systems }\end{array}$ & $\begin{array}{l}\text { Practicing second-level } \\
\text { K-tools } \\
\text { Operation standard }\end{array}$ \\
\hline
\end{tabular}

Source: EKI (2014c)

The activities in each step are self-explanatory, and we believe that readers will understand them as they are set out here. As noted above, the first 18 consultants have already graduated with an MSc in Kaizen, 16 consultants are in second year, and 22 are in first year. EKI has also plans to introduce a $\mathrm{PhD}$ program in Kaizen in 2018 with the support of JICA. This will further increase local capacity.

\subsubsection{GTP II Plan (2015-2020)}

EKI has developed a second growth and transformation plan corresponding to the national growth and transformation plan (EKI 2015a, b, c). The two major areas of focus are transferring the second-level Kaizen and 
Table 5.8 Third-level Kaizen

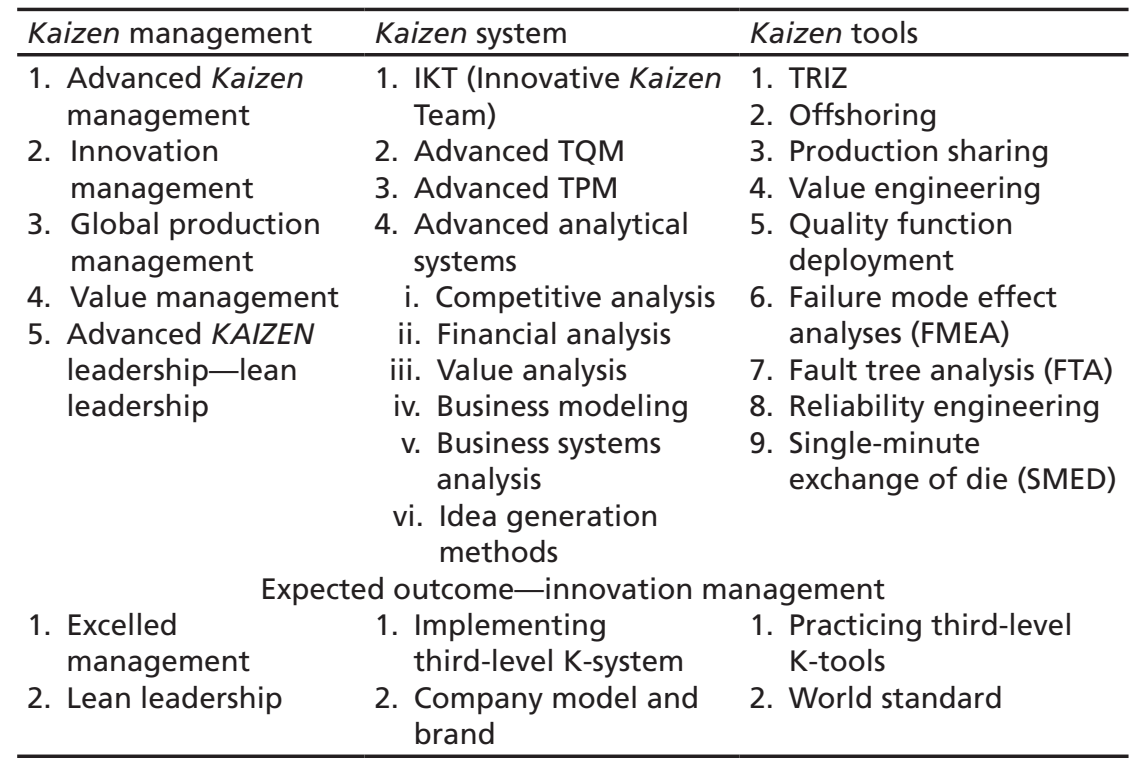

Source: EKI (2014c)

\section{EK-TIISO MODEL}

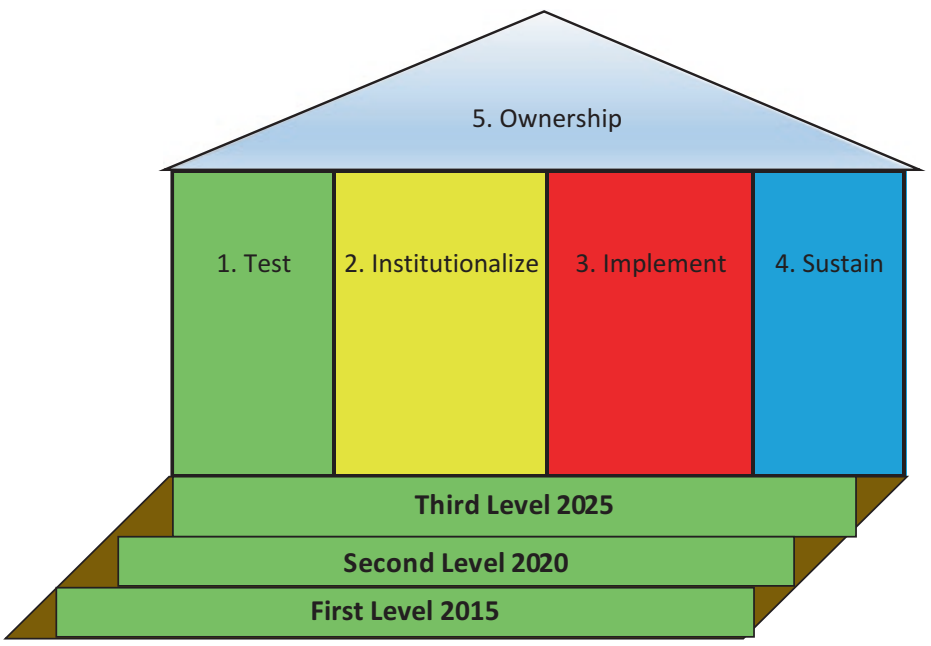

Fig. 5.2 TIISO Model. (Source: Mekonen 2015b) 


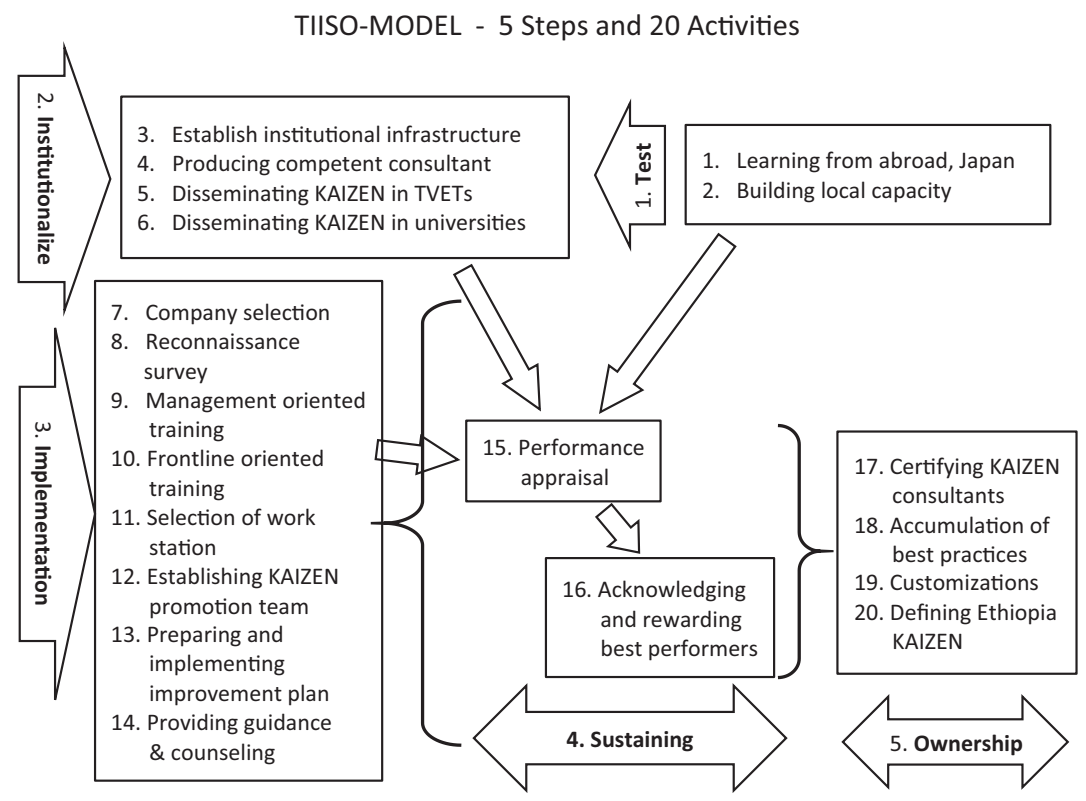

Fig. 5.3 TIISO Model- 5 steps and 20 activities. (Source: Mekonen 2015b)

disseminating Kaizen in the priority areas stipulated in GTP II. This plan is also taken as a reference to provide support for the building of a center of excellence for Kaizen. A summary of the plan is presented below.

\subsubsection{Vision of EKI}

The EKI vision is "being a center of excellence for transformed working culture and innovation management skill." Specifically, the goals are as follows:

1. Introducing Kaizen in the export and import manufacturing industries by training management and frontline workers and organizing them in KPTs with the ultimate goal of improving quality and productivity, reducing waste and defects, improving work safety, and satisfying international buyers' requirements to develop competitiveness for export earnings and substituting imports. 
2. Support the Human Resouce Develpment (HRD) objective of producing a competent workforce by introducing Kaizen thinking and principles starting from kindergarten and continuing throughout the education system to produce a transformed future generation of citizens.

3. Introducing Kaizen in the construction industry and infrastructure development to improve the quality of work, reducing waste in working processes, and standardizing every activity.

4. Implementing Kaizen in major service organizations directly influencing the competitiveness of the manufacturing industry.

\subsubsection{Basic Direction of Kaizen Movement}

1. Promoting and maintaining a comprehensive understanding of Kaizen and improving the quality of capacity building by transferring Kaizen philosophy from the source, that is, Japan, step by step, based on the learning capability of Kaizen consultants and absorptive capacity of companies.

2. Giving top priority to the manufacturing industry and associated organizations directly contributing to manufacturing competitiveness.

3. A long-term vision to lay the foundation for longer time spans focusing on producing transformed generations.

\subsubsection{Objectives}

The overall objective of the Kaizen movement during GTP II is to improve the quality of products and services, enhance productivity and competitiveness by providing training for management and frontline workers, and organizing them into KPTs. The goals are to train 98,000 workers and create $10,500 \mathrm{KPT}$ in the manufacturing industry, 17,140 workers and $2450 \mathrm{KPT}$ in HRD, and 20,000 workers and $2000 \mathrm{KPT}$ in construction and basic services. The overall figure will be 135,140 management and frontline workers and 14,950 KPTs. 


\subsection{Counting the Results: Achievements, Success Factors, and Challenges}

The achievements of Ethiopian Kaizen can be viewed from two perspectives. These are the results achieved by the three JICA-supported projects, discussed in Sects. 5.1, 5.2, and 5.3, and EKI's own efforts, which are considered in more detail here.

At the time when EKI was first established, two activities were running side by side: CRT programs in the second project and CRT sessions run by KU members for the newly recruited EKI consultants. EKI started owning the dissemination of Kaizen from the very beginning. Following every six-month training, each new batch of participants joined the Kaizen movement led by EKI management. The Kaizen movement began by working with large-scale companies like the sugar and textile industries as well as huge construction projects. It was a challenge and an opportunity for the fast-track development of EKI consultants. EKI reached 458 institutions between 2012 and 2016. The details of institutions reached, number of trainees, and KPTs formed are given in Tables 5.9 and 5.10 (EKI 2012, 2013, 2014d, 2015c, 2016c).

Table 5.9 Different institutions reached by EKI

\begin{tabular}{|c|c|c|c|}
\hline S.N. & Institutions & & Number \\
\hline 1 & Manufacturing & & 80 \\
\hline 2 & Services & & 12 \\
\hline 3 & Construction & & 11 \\
\hline 4 & Universities & & 16 \\
\hline \multirow[t]{2}{*}{5} & TVETs & Institutions & 9 \\
\hline & & Regions & 7 \\
\hline 6 & Schools & & 10 \\
\hline 7 & Kindergartens & & 5 \\
\hline 8 & City-based movement & Cities & 4 \\
\hline 9 & Towns & & 2 \\
\hline \multicolumn{2}{|c|}{ Total by EKI } & & 166 \\
\hline \multirow[t]{2}{*}{10} & Projects & MSES & 198 \\
\hline & & LMEs & 109 \\
\hline \multicolumn{2}{|c|}{ Grand total } & & 473 \\
\hline
\end{tabular}

Source: Compiled from EKI Annual Reports (2012-2016) 
Table 5.10 Number of trainees and organized KPTs

\begin{tabular}{llllll}
\hline & & \multicolumn{3}{l}{ Trainees } & \\
\cline { 3 - 5 } S.N. & Year & M & F & Total & KPTs \\
\hline 1 & $2012-2013(2005$ E.C) & 9363 & 2633 & 11,996 & 1315 \\
2 & $2012-2014(2006$ E.C) & 2275 & 9923 & 12,198 & 2275 \\
3 & $2014-2015(2007$ E.C) & 6944 & 5171 & 12,115 & 1789 \\
4 & $2015-2016(2008$ E.C) & 9034 & 6059 & 15,093 & 1790 \\
5 & $2016-2017(2009$ E.C) & & & 17,552 & 2489 \\
& & 27,616 & 23,790 & 68,954 & 9658 \\
\hline
\end{tabular}

Source: Compiled from EKI Annual Reports (2012-2016)

EKI has developed criteria to collect data before and after implementation of Kaizen. Every month, implementing companies provide reports to EKI on the progress of improvements using reporting formats developed by the institute. The reporting formats have two parts, namely quantitative and qualitative achievements.

During 2012-2013 and 2013-2014, improvements within 48 companies were assessed using specific Kaizen elements. The range of improvements before and after Kaizen implementation are summarized in percentages as follows (EKI 2015b):

1. Secured from 52.6 to 9053 square meters of additional workspace after sorting and set-in-order (reorganization);

2. Improvements in labor productivity ranging from $1.29 \%$ to $60 \%$;

3. Improvements in capacity utilization of machinery from $25 \%$ to $75 \%$;

4. Reductions in defects from $57.1 \%$ to $5.0 \%$;

5. Reductions in costs ranging from $6 \%$ to $33 \%$;

6. Reductions of occurrences of accidents in companies from the rate of $49.5 \%$ to $14.3 \%$.

At the lower end of the scale of improvements in labor productivity are high-tech industries, while much greater improvements were experienced by textile and leather companies. The labor productivity and capacity utilization levels indicate how the companies were disorganized and resources were underutilized before the implementation of Kaizen. The gains of up to 9053 sq. $\mathrm{m}$ in workspace mean additional free space for investment or expansion without incurring any costs-something that has happened in many companies. Although the gains in all cases are 
impressive, reductions of defects from $57.1 \%$ to $5.0 \%$, reductions in costs in the range of $6 \%$ to $33 \%$, and reductions in accidents from $49.5 \%$ to $14.3 \%$ are drastic changes that motivated implementing companies to continuously pursue Kaizen. This has further generated demand by many companies for Kaizen activities.

One example of a Kaizen activity in a big company is offered here as a brief case study to show the magnitudes of changes that can occur. Metehara Sugar Company (Metehara 2016) was established by Dutch H.V.A in 1970. Its crushing capacity is 17,000 quintals of sugar cane, which should produce 1700 quintals of sugar. It has 2461 permanent, 776 permanent contract, 113 contract, and 3524 temporary employees-6874 employees in total. Out of this large number, there are only 186 professional and 830 semi-professional workers, while the remaining 5858 are semi-skilled. The sugar estate experienced sharp declines in production from 2009 to 2012. It was unable to fulfill its annual plan and its performance compared to attainable capacity fell from $92.3 \%$ in 2009 , $78.4 \%$ in $2010,71.6 \%$ in 2011 to $61.3 \%$ in 2012 . All the benefits of management and workers had been suspended, and the industrial culture was characterized by heavy confrontations between management and workers. In short, it was a totally demotivating environment. In 2013, EKI conducted a massive training program and many KPTs were formed. Almost all company employees were given multiple rounds of training for over three months and organized into KPTs (see Table 5.11).

After the introduction of Kaizen, annual production of sugar increased from $61.3 \%$ in 2012 to $88.4 \%$ in 2013 compared to the factory's attainable capacity. Similarly, ethanol production increased from $69.5 \%$ in

Table 5.11 Number of KPTs organized in Metehara Sugar Industry

\begin{tabular}{llc}
\hline S.N. & Departments & No. of KPTs \\
\hline 1 & General Manager & 16 \\
2 & Agricultural Operation & 747 \\
3 & Factory Operation & 158 \\
4 & Human Resource Development & 19 \\
5 & Finance & 8 \\
6 & Supplies and Facility Management & 64 \\
& Total & 1012 \\
\hline
\end{tabular}

Source: Metehara (2016) 
2012 to $74.6 \%$ in 2013 . Sugar production grew by $43.98 \%$ and daily sugar cane crushing capacity increased by $23 \%$. The improvements in daily sugar production capacity and overall time efficiency were $35 \%$ and $20 \%$, respectively. From each quintal of sugar, production costs were reduced by 23 birr and annual fuel costs were reduced by 1.2 million birr (both in nominal value).

In 2014, compared to the performance in 2013, working hours wasted were reduced by $30 \%$, sugar production waste was reduced by $2.4 \%$, annual sugar crushing capacity improved by $5 \%$, daily sugar production capacity increased by $3 \%$, and sugar cane yield increased by $5 \%$. The two-year performances indicate the continuous improvements by the company. The overall improvement in monetary value is provided in Table 5.12, indicating the percentage improvement and monetary gains for this one company. To present the bigger picture, the total monetary values or gains in improvement in each year since Kaizen was introduced to Ethiopia are summarized in Table 5.13.

The most important change, over and above these quantitatively explained results, has been the attitudinal change, which is highly significant. Developing confidence in bringing change, bridging the gap

Table 5.12 Monetary value (nominal) of Kaizen achievement in Metehara Sugar Estate

\begin{tabular}{ll}
\hline Year & Improvements in millions birr \\
\hline 2013 & 35 \\
2014 & 275 \\
2015 & 423 \\
Total & 733 \\
\hline
\end{tabular}

Source: Metehara (2016)

Table 5.13 Monetary gains (nominal value) of Kaizen in Ethiopia

\begin{tabular}{lll}
\hline S.N. & Year & Amount in million birr \\
\hline 1 & $2011-2012(2004$ E.C) & 25 \\
2 & $2012-2013(2005$ E.C) & 75 \\
3 & $2013-2014(2006$ E.C) & 500 \\
4 & $2014-2015(2007$ E.C) & 1121 \\
5 & $2015-2016(2008$ E.C) & 448.5 \\
Total & 2169.5 \\
USD equivalent & $\$ 105$ million \\
\hline
\end{tabular}

Source: EKI (2016c) 
between management and workers through total participatory activities by involving the whole workforce was a far-reaching result in maintaining the momentum of continuous improvement. Most companies that introduced Kaizen have continued to improve their workplace in terms of (1) orderliness and cleanliness, (2) worker safety, (3) worker motivation by increasing salaries and providing bonuses, (4) product quality improvements by reducing defects and the need for repairs, (5) productivity improvements by reducing waste, and (6) delivery time improvements in meeting the requirements of their customers. Although the magnitude of change differs between companies, all implementing companies have attained such results.

EKI has developed an annual Kaizen award system to motivate companies, KPTs, and individuals. Companies that have implemented Kaizen, along with KPTs and individuals, compete every year for the National Kaizen Award. The award, presented by the Prime Minister, is issued each year to three companies/institutions, three KPTs, and three individuals from each category of manufacturing, education, services, construction, along with three overall winners across all of the categories.

A review of the various reports issued by JICA and EKI shows that Kaizen in Ethiopia is considered to be a successful and flagship project. EKI's roadmap and strategies are now taken as a model for many African countries. Parliament members and high-level officials from the Government of Japan, high-level officials from JICA-including the presidents, vice presidents, and other officers-have visited EKI to observe its performance. EKI received the JICA President's award for successful accomplishments of the projects in 2015.

What are the secrets—if any at all—behind such successes? What are the limitations despite the success stories? Eleven major factors were identified by EKI and discussed nationwide (EKI 2016b). These factors are explored both from the observed positive and negative effects where applicable.

\section{(i) Continuous support of JICA}

JICA's support is responsible for the lion's share of the success, as discussed intensively in this chapter. The support includes building the capacity of the consultants, providing vehicles and equipment. EKI has 
wisely and strategically optimized the resources provided by JICA for the benefit of the project. There was a continuous dialogue with experts on how to transfer Kaizen concepts and technologies that eventually led EKI to craft a roadmap and detailed time-framed long-term strategy. The efforts made by EKI to successfully realize each project motivated JICA to provide continuous support. EKI was careful about ensuring that it succeeded in every aspect of JICA's stringent evaluation by providing evidence and facts. This created a sense of trust and mutual benefits between JICA and EKI.

\section{(ii) Commitment of political leadership}

While Kaizen was initiated by the late Prime Minister Meles Zenawi, the current Prime Minister Hailemariam Desalegn has also paid significant attention to it. The National Council of Kaizen is chaired by the Prime Minister, and the budget of EKI has been approved by Ministry of Finance and Economic Development annually with no or little remarks. The Ministry of Public Service and HRD, to whom EKI is presently accountable, is highly enthusiastic and supportive of Kaizen based on the belief that it is an important reform tool not only for manufacturing but also to improve public service delivery.

(iii) Clear vision, road map, and strategy

EKI has developed clear vision to become a center of excellence for Kaizen in Africa and it has shared its vision with JICA and other African countries, which have tried to learn from the experience of EKI through participation in forums and conferences. It has also successfully promoted its vision during the nationwide Kaizen month in September. EKI has designed a clear roadmap over a 15-year period to transfer Kaizen from its origins in Japan. The roadmap is presented in detail in the TIISO Model of 5 steps and 20 activities. Clear strategies are designed that are now part of the growth and transformation plan.

(iv) EKI management commitment and young Kaizen-cultured consultants

The top management leads through learning, directly participating in trainings, implementation, evaluation, and continuously discussing the 
process with JICA experts. It is also conceptualizing the roadmap, model, and strategies and making it open for discussion for all. The management has followed a democratic leadership style since EKI is not a bureaucratic institution but is instead reform and knowledge-based. All members of the institution, regardless of their status and position, have a full right to demonstrate and air their ideas, comment on anything that seems wrong, and suggest better ideas for improvement. EKI consultants are energetic and always eager to know more.

Daily, weekly, monthly, quarterly, and annual evaluation system and procedures have been put in place. A team of two or three consultants is deployed to each company and they stay for a month and a half in companies that are often far away from Addis Ababa. They evaluate their daily activities as a team and through individual performances. A weekly report is generated and sent to EKI by each team. The concerned directorate compiles a monthly report that is discussed at the working unit and management meeting levels and sent to the ministry. The reports focus not only on activities but also on results by comparing planned against actual accomplishments. The results are presented in terms of qualitative and quantitative values to show changes before and after implementation, as discussed above. For any shortfalls there must be a compensating plan. The performance evaluation of each management member and consultant is based on all these processes.

\section{(v) Motivating career structure, pay, and benefits}

Although salary is not the only factor in job satisfaction, it is an important element for recruiting and maintaining capable consultants. EKI is a public organization and its pay and benefits are in the highest category of public service salary ranges.

\subsubsection{Challenges}

Although EKI benefits from these encouraging factors, there are also a number of challenges. Six such factors that were identified and discussed by EKI on many occasions are presented here: 
(vi) Mindset

It is obvious that any change program has quick recipients, laggards, and resisters. Some companies are reluctant to start activities after they are selected and the plan is prepared. They fear that the training and implementation may take time away from production or routine activities. They tend to believe that the way they are operating is fine, and they are comfortable with the status quo. Due to the fact that local markets absorb whatever is thrown at it, there are no consequences for poor quality or low productivity. If export products produced under subsidies through different incentives do not meet the expected quality, they can still be sold in local markets.

Two tendencies can be observed in some companies. The first one fears EKI consultants who, as public employees, may take some damaging information to government agencies - particularly tax authorities. The second issue is that they become totally reliant on EKI consultants to do everything for them while they wait. In some cases, the different change tools tried were not as productive as expected and there was a tendency toward reluctance to try new ones. Despite the positive effects of BPR on improving service delivery, the way it was implemented in some organizationsin terms of restructuring, placement, and layout-has created suspicion over reform tools. In some factories, particularly export-led ones, the practice of benchmarking has not delivered results to the expected level or investment. Both lack employee participation at the Gemba level ${ }^{5}$ and fail to develop the knowledge and skills of workers for the job.

EKI management and consultants make extended efforts to convince company managers and workers regarding the unique character of Kaizen and its benefits to all. They explain the main principles of Kaizen as continuous improvement, as fully participatory, as beneficial to all members of the company-even for self-improvement - and as creating opportunities for business expansion, thereby benefiting all members of society.

It is through these considerable efforts that changes of attitude are brought about. Some companies are quick to comprehend and become committed early on in the process.

\footnotetext{
${ }^{5} \mathrm{Gemba}$ is a Japanese word to represent a workplace.
} 


\section{(vii) Securing the commitment of owners and managers}

In all countries-including Japan-Kaizen has succeeded where the commitments of owners and managers have been secured. The same is true in Ethiopia. Where owners and managers committed themselves to implementation, sustainable improvements were guaranteed. By contrast, there are some companies that are either reluctant to start or quick to withdraw.

\section{(viii) Frequent turnover of managers and Kaizen leaders}

EKI has nurtured strong managers and Kaizen leaders in most companies that implemented Kaizen. These managers and leaders are in-demand from many other companies. In large public enterprises, strong managers and Kaizen leaders are transferred to other departments or promoted internally. The causes of staff turnover might be considered healthy in a competitive market environment. However, when it happens without a clear succession, or handover of responsibilities, or disrupts the sustainability of improvement efforts, it can become counterproductive. This has been noticed in several companies. EKI has developed a succession plan that it tested on itself first and is now promoting it to implementing companies to counteract the negative impacts of turnover.

\section{(ix) Distorted understanding of Kaizen}

Kaizen is one of the most frequently misunderstood of all changemanagement concepts and management philosophies. Different literature gives different meanings to it and, even in a single volume, one may find different definitions. EKI has discussed the concept with Japanese experts and professionals for over three years but consensus on a universal definition is yet to be reached. For instance, two different ways of defining the term can be observed in the two manuals developed by the two projects. Some definitions underplay the philosophical aspects and reduce the process to mere technical activities. Others divorce their definitions from the concepts and systems developed in the context of Kaizen, making it a part of a system, instead of the system being part of it. For example, the basis for the idea of total quality management system is companywide quality control or total quality control (Ishikawa 1985) developed in Japan 
between the 1960s and 1980s. In the 1980s, the USA explored these principles and crafted TQM in their own way. In the 1990s, Japan came up with a TQM system based on its experiences, incorporating Quality Control Circle (QCC)s, as well as problem-solving steps and tools (Umeda 2001). This fact is well illustrated in the Handbook of TQM and QCC (IADB 2003). Hence, while Japanese TQM is part of Kaizen, Western thinkers tend to view Kaizen as part of TQM. One limitation of Western TQM is its separation from quality-control activities and problem-solving tools, which are also the products of Kaizen. Now this problem is believed to be solved by the definition and explanations provided in Chap. 1 of this book. This provides an opportunity to create a common language among JICA officers, JICA experts, and recipient countries.

\section{(x) Limitations of quick learning and expanding knowledge}

One issue that is frequently discussed at EKI during quarterly and annual evaluations is the limitation of learning quickly from the JICA experts and the need to broaden knowledge through local customization and reading. One of the prerequisites for Kaizen, as learned from JICA experts, is having full knowledge of Kaizen. While most people try to do this, some management members and consultants do not progress beyond the PowerPoints provided by the experts without further improvement or customizing them to suit to different audiences. JICA experts have developed their own methods from their experiences in different courses and there is no standard training on a given course, for example, on $5 \mathrm{~S}$. Although learning from the experiences of different experts might be good, this has sometimes created confusion and at times become a point of difference between consultants. As explained above, there is a tendency by few consultants to be satisfied with what they know and a reluctance to read and learn more to expand their knowledge, customize, and write about their own cases, and so on.

\footnotetext{
${ }^{6}$ In December 2003, a workshop for knowledge exchange between Japan, Asia, Latin America, and Caribbean was organized at the Inter-American Development Bank (IDB) headquarters on the topic of quality control. As a follow up activity, to develop and disseminate TQM and QCC, a team was formed by the Development Bank of Japan (DBJ) and a handbook on TQM and QCC was prepared.
} 


\section{(xi) Information management}

One of the Kaizen principles is basing decisions on facts. Ensuring that there are complete and accurate data both before and after implementation is indispensable for evaluation. Sometimes, in the processes of training before kickoff, some people start implementing what they have learned every day. Moreover, it can be difficult to get data on productivity, defects, and delivery delays, mainly due to lack of registering these issues in a log book. KPTs (QCCs) forget to register improvements they made, meetings, ideas generated, and so on. Marketing departments lack data on the number of customers, frequency of orders, lost markets, the number of lots or product types, and so on. In some cases, it is difficult to obtain financial data. Although companies have to protect their secrets, and this is acceptable, in some cases there is an extreme view about withholding all data.

\subsection{The Ethiopian Kaizen Model: A Shopping Arcade for Africa?}

Drawing lessons from the experience of a given country is not an easy task. Eight 'takeaway' determinants for success from this research are offered. These are:

(i) Strong commitment of top leadership at all levels;

(ii) Establishment of a national organizational framework with a clear vision, mission, and leadership;

(iii) Optimum utilization of Kaizen projects;

(iv) Grassroot-level promotion;

(v) Customization and standardization of training programs and materials;

(vi) Development of capable consultants;

(vii) Establishment of systems of recognition and awards; and (viii) Sustaining Kaizen activities.

Considering these determinants while exploring the Ethiopian case is believed to be helpful in drawing tangible lessons. A brief discussion on each of these points, while referring to the supporting evidence, is offered below without or with little repetition of previously explored points. 


\subsubsection{Strong Commitment of Top Leadership at All Levels}

In different parts of this chapter, the commitment of the late Prime Minister to initiating the transfer of Kaizen and the current Prime Minister to sustaining political leadership have been discussed. Such commitments are confirmed by the following facts:

(a) It was the late Prime Minister who requested the support of JICA for the Kaizen project and who provided support for the establishment of EKI.

(b) It is the current Prime Minister who has established and chaired the National Kaizen Council and supported the expansion and benefits of EKI.

(c) There were frequent exchanges of letters between the Ethiopian government and JICA as well as GRIPS Development Forum to discuss issues related to Kaizen and prepare an agenda for discussions.

(d) The budget requested by EKI has been fully endorsed each year.

(e) The success of EKI is partly due to committed company managers and Kaizen leaders.

(f) Attention from the minister and state ministers on supervising and receiving reports on its performance.

\subsubsection{Establishing a National Organizational Framework with a Clear Vision, Mission, and Strong Leadership}

$\mathrm{EKI}$ is an outcome of $\mathrm{KU}$ and the successful execution of its pilot project. If the project had not been successful, government commitment might have been halfhearted. However, the government and JICA followed up with frequent visits and evaluations of performance reports right from the beginning. The dissemination plan indicated the necessity of having a strong institution to expand on results attained during the pilot project. To establish the institute on a concrete foundation, the experiences of 13 countries were explored and customized to meet the needs of Ethiopia. 
This process helped KU to acquire knowledge to prepare a Formation Paper and Gazette. The Gazette explicitly outlined the far-reaching duties of EKI. The commitment of the Prime Minister easily convinced the Council of Ministers to accept and adopt it. The first Director General assigned to EKI has been able to lead the project and has already established a basic knowledge platform. The central belief was to lead by knowledge and not to repeat mistakes that had occurred elsewhere. This was done by exploring the institutionalization study and careful consideration of the direction set in that study for successful accomplishment. Engagement in the project began not only by waiting for the experts but also under the assumption of equal leadership. Systems and procedures were designed that helped with the acquisition of knowledge on Kaizen rapidly, and EKI cultivated a learning organization culture. Young and talented staff members were selected as members of EKI and they have been trained continuously. EKI always attempts to create a motivating working environment and team culture.

EKI has carefully learned from the models of Japan and Singapore. However, since these two cases are quite different from the Ethiopian situation, EKI developed its own vision, roadmap, model, and strategies. It has shared these with JICA experts and officials, discussed them with government officials and institutions and popularized them among the public through different media networks. This has helped to create broadbased awareness and develop confidence in the sustainability of Kaizen activities. This is what EKI learned, practiced, and succeeded in sharing with others.

\subsubsection{Optimum Utilization of Kaizen Projects}

Among many factors that make EKI successful is strong project management. In all projects, EKI's management is heavily involved. These projects were not left to JICA's experts. There was continuous discussion on the preparation of the project design matrix (PDM), work plan, detailed activities, feedback and evaluation on the CRT and ICT, interim and final project evaluations, as well as the contents of teaching materials and manuals. EKI took the initiatives to customize Kaizen for the Ethiopian situation. 


\subsubsection{Grassroot-Level Promotion}

The cases of successful countries like Singapore show that creating nationwide awareness is one of the most important factors for success. In Ethiopia, Kaizen was introduced not only in the manufacturing industry but also in different service organizations, including schools. In some cities and towns where big companies like sugar and textile companies implemented Kaizen, workers took the ideas home to their families. Many public and private media channels were mobilized to introduce the concept of Kaizen and disseminate the results attained to the public. Training was given to communicators and journalists. High-level officials including the prime ministers and frontline workers were interviewed and broadcast on NHK in Japan, the BBC, and CNN. Other foreign broadcasting channels have also covered Ethiopian Kaizen.

\subsubsection{Customization and Standardization of Training Program and Materials}

Kaizen itself is an outcome of customization. No two countries are similar enough for copy-and-paste-style projects to be successful. The unique features of each country should be taken into account in the implementation of Kaizen; however, its novelty and quality should be maintained. For instance, the concept of $5 \mathrm{~S}$ and $M U D A$ cannot be changed, but the way it is presented in training and the manner of implementation could differ from factory to factory, country to country, and so on. From the study of the experience of 13 other countries, EKI has learned that customized and standardized teaching materials are one of the key factors for success. EKI has consistently modified and customized teaching materials offered by JICA consultants. This customization takes two forms: firstly, the development of one set of customized master teaching materials and, secondly, to further customize the materials to suit each sub-sector like textiles, leather, metal, construction, and so on.

What EKI has learned from the failure cases of other countries is that a focus on the techniques and short-term targets does not lead to fullfledged success. Particularly, for a country like Ethiopia, attitudinal change is very important, and it must receive high priority. This could be 
realized through comprehensive understanding of Kaizen, strong team work, integrated companywide activities by top and middle management, and frontline workers. In EKI's training materials, this has been emphasized. The results attained so far bear witness to the importance of attitudinal change to sustain improvements.

\subsubsection{Developing Capable Management and Consultants}

To maintain the continuity and sustainability of the Kaizen movement, the presence of strong management and skilled consultants is indispensable. EKI is supported by JICA to develop its consultants. It has also initiated its own programs in collaboration with universities to develop local capacity-building capability. This has two advantages: it enhances the conceptual and analytical capacity of consultants and creates opportunities for university instructors to gain some experience of Gemba. EKI has developed a succession plan to nurture leaders from inside. The plan consists of developing two layers of management; top management and middle management. The overall plan is handled by the director general for top management and by deputy director generals for middle management. EKI's cross-functional KPTs are sources for cultivating middlemanagement staff. The leaders of cross-functional KPTs are the first layers for recruitment and promotion to fill the vacancy of middle management. As has been indicated above, EKI consultants are always eager to learn and know more, and are motivated to provide training, consultancy, and follow-ups throughout the year, usually staying in companies for a month or two and paying frequent visits every quarter. EKI pays allowances and the cost of accommodation for its consultants.

\subsubsection{Establishing a System of Recognition and Award}

One of the duties of EKI, as stipulated in the proclamation, is to establish recognition and award systems. As noted above in the discussion about the development of the new organizational structure, this activity has been given due regard. The Department of Certification, Registration, 
and Awards is led by a Deputy Director General. Every year there is a competition among companies, KPTs and outstanding individuals for Kaizen awards. There is also strong competition among EKI consultants to produce excellent companies and KPTs. The award is covered by major media companies and it is an important aspect of promotion.

\subsubsection{Sustaining Kaizen Activities}

JICA's approach to Kaizen promotion, regardless of country, is to raise awareness of Kaizen activities through the creation of model companies. This was true in Ethiopia. Demand for Kaizen was created by the pilot project and sustained in subsequent projects and ownership of EKI. The results that have been achieved and popularized through the media have resulted in increased demand from other companies, and EKI is now being inundated by many requests. Continuous and sustained demand is secured by the quality of training, consultancy, and follow-up services.

In a nutshell, ensuring political commitment, establishing an institutional infrastructure that owns and leads a national Kaizen movement, developing qualified and devoted local consultants, securing the commitment of implementing institutions, generating demand through grassroot-level promotion for Kaizen activities, and motivating high performers are among the major factors in sustaining Kaizen activities.

To conclude, while the above points are the key factors to be considered in terms of Kaizen programs, this should not limit readers' freedom to delve more deeply into the chapter. To answer the question of the title of this section: yes, this study demonstrates that EKI's approach can be considered as a useful way for Africa.

\section{References}

Ethiopia Kaizen Institute. (2011). Proclamation on the Formation of EKI Number 256/2011.

Ethiopia Kaizen Institute. (2012). Annual Reports.

Ethiopia Kaizen Institute. (2013). Annual Reports.

Ethiopia Kaizen Institute. (2014a). Strategic Direction of Ethiopia Kaizen Movement. 
Ethiopia Kaizen Institute. (2014b). Comprehensive Understanding of Kaizen and Implementation Strategy.

Ethiopia Kaizen Institute. (2014c). Strategic Framework of Ethiopia Kaizen.

Ethiopia Kaizen Institute. (2014d). Annual Reports.

Ethiopia Kaizen Institute. (2015a). EKI Growth and Transformation Plan (GTP II) 2015-2020.

Ethiopia Kaizen Institute. (2015b). Compiled Best Experience.

Ethiopia Kaizen Institute. (2015c). Annual Reports.

Ethiopia Kaizen Institute. (2016a). EKI Revised Organizational Structure.

Ethiopia Kaizen Institute. (2016b). Discussion Paper Prepared on the Occasion of Kaizen Month.

Ethiopia Kaizen Institute. (2016c). Annual Reports.

Federal Democratic Republic of Ethiopia. (2011). Proclamation 256/2012.

Federal Democratic Republic of Ethiopia. (2015). Second Growth and Transformation Plan.

Hosotani, K. (1989). QC-teki Mondai Kaiketsuho (The Quality Control Problem Solving Approach). Tokyo: JUSE Press.

Imai, M. (1986). Kaizen: The Key to Japan's Competitive Success. New York: McGraw-Hill.

Inter-American Development Bank. (2003). Handbook for TQM and QCC Volume I and II.

Ishikawa, K. (1985). What Is Total Quality Control? The Japanese Way (trans. Lu D.J.) Englewood Cliffs: Prentice Hall. Originally published as a Japanese book entitled Nihonteki Hinshitsu Kanri in 1981. Tokyo: JUSE Press.

Japan International Cooperation Agency. (2011a). The Study on Quality and Productivity Improvement (Kaizen) in the Federal Republic of Ethiopia, JICA ILD-JR 11-011.

Japan International Cooperation Agency. (2011b). Ethiopia Kaizen Manual. Japan International Cooperation Agency. (2014a). The Project for Capacity Building for Dissemination of Quality and Productivity Improvement (Kaizen) in the Federal Republic of Ethiopia, JICA IL-CR (10) 14-129.

Japan International Cooperation Agency. (2014b). The Project for Capacity Building for Dissemination of Quality and Productivity Improvement (Kaizen) in the Federal Republic of Ethiopia Kaizen Manual.

Japan International Cooperation Agency. (2016). The Project on Capacity Development for Kaizen Implementation for Quality and Productivity Improvement and Competitiveness Enhancement, JICA Progress Report (NO.1).

JUSE (QC Circle Headquarters). (1985). How to Operate QC Circle Activities. Tokyo: JUSE Press. 
Kato, I., \& Smalley, A. (2011). Toyota Kaizen Methods, Six Steps to Improvement. New York: Productivity Press.

Liker, J. K. (2004). The Toyota Way. New York: McGraw Hill.

Mekonen, G. T. (2014). Kaizen ltqnajena Asetemamagn lwete (Kaizen for Integrated and Sustainable Change). Addis Ababa: Messele Multimedia and Printing Works.

Mekonen, G. T. (2015a). Kaizen ltqamawi lwete, lamrare leheqtena ltewdadarinte (Kaizen for Institutional Transformation, Leadership Excellence and Competitiveness). Addis Ababa: Messele Multimedia and Printing Works.

Mekonen, G. T. (2015b). EKI Annual Booklet edition 3 number 3: On Three Generations of Kaizen Transfer and Development Model, pp. 11-20.

Mekonen, G. T. (2017). Kaizen Yegna Model (Our Kaizen Model). Addis Ababa: Mega Printing and Distribution Company.

Metehara Sugar Factory. (2016). Annual Report.

National Graduate Institute for Policy Studies. (2016). Records of Ethiopia-Japan Industrial Policy Dialogue, Vol. II, GRIPS Development Forum. Tokyo: National Graduate Institute for Policy Studies.

Osada, H. (2013). Kaizen Best Practices of Quality Control Circles.

Sato, K. (2011). Framework of Ethiopia Kaizen Institute.

Suzuki, T. (1994). TPM in Process Industries. New York: Productivity Press. Originally published as a Japanese book entitled Sochi Kogyo no TPM in 1992. Tokyo: Japan Institute of Plant Maintenance.

Umeda, M. (2001). Seven Key Factors for Success on TQM. Tokyo: Japanese Standards Association.

Open Access This chapter is licensed under the terms of the Creative Commons Attribution 4.0 International License (http://creativecommons.org/licenses/ by/4.0/), which permits use, sharing, adaptation, distribution and reproduction in any medium or format, as long as you give appropriate credit to the original author(s) and the source, provide a link to the Creative Commons license and indicate if changes were made.

The images or other third party material in this chapter are included in the chapter's Creative Commons license, unless indicated otherwise in a credit line to the material. If material is not included in the chapter's Creative Commons license and your intended use is not permitted by statutory regulation or exceeds the permitted use, you will need to obtain permission directly from the copyright holder. 